\title{
Synthesis of antibacterial polymers from 2-dimethylamino ethyl methacrylate quaternized by dimethyl sulfate
}

\author{
Huajiang Zuo ${ }^{1,2}$, Dingcai $\mathrm{Wu}^{1,3}$ and Ruowen $\mathrm{Fu}^{1,3}$ \\ An antibacterial quaternary ammonium acrylic monomer (1) was synthesized by quaternization of 2-dimethylamino ethyl \\ methacrylate with dimethyl sulfate. This synthetic route to quaternary ammonium salt monomer proved to be of high yield and \\ lower cost than that used to synthesize alkyl halide. The corresponding homopolymers (2) were then obtained by free radical \\ polymerization using potassium persulfate as the initiator. The chemical structure was characterized by Fourier transform \\ infrared and ${ }^{1} \mathrm{H}$-nuclear magnetic resonance, and molecular weights (MWs) were compared by the viscosity method. Factors \\ influencing the synthesis of (1) and (2) were also investigated. Antibacterial activity was tested against Escherichia coli and \\ Staphylococcus aureus using a minimum biocidal concentration test and the shaking flask method. Monomer (1) exhibited \\ moderate antibacterial activity; however, the polymers had significantly stronger antibacterial activity than the monomer. \\ Therefore, their potential for antibacterial application was established. Similar to other quaternary ammonium compounds, \\ the antibacterial activity of the polymers depended on their MW, and this dependence varied with the type of testing \\ microorganisms.
}

Polymer Journal (2010) 42, 766-771; doi:10.1038/pj.2010.63; published online 14 July 2010

Keywords: antibacterial; 2-dimethylamino ethyl methacrylate; dimethyl sulfate; synthesis

\section{INTRODUCTION}

In recent years, scientists have paid much attention to the development of new materials with antibacterial properties so as to prevent bacterial infection and protect human health. Antibacterial materials have been widely used in textiles, ${ }^{1,2}$ food packaging, stainless steel ${ }^{3,4}$ and medical items. ${ }^{5,6}$

Previously, research on antibacterial materials concentrated mainly on the physical incorporation of biocides, which are released into the surrounding environment to exert antibacterial activity. ${ }^{7-10}$ The release rate should be carefully controlled. If the biocides release too slowly, a desirable antibacterial activity cannot be achieved. Too fast a release, however, would result in unnecessary waste and hasten the expiration of the biocides. Furthermore, no matter how hard we try to control the release rate, the materials eventually lose their biocidal activity because of the shortage of active components. This makes them unfit for long-term application. In addition, the threat of residual toxicity and inability to kill airborne bacteria limit their applications.

Recently, interest has shifted to materials with inherent antibacterial properties that kill bacteria on direct contact without the need to release active components. These materials show promise in retaining antibacterial activity and reducing the risk of toxicity. Polymeric quaternary ammonium compounds (PQACs) are among commonly used inherently antibacterial materials, as they have good antibacterial activity, low volatility, high chemical stability, low toxicity and low skin irritation potential. ${ }^{1-13}$ They have been successfully used in the antibacterial surface modification of materials. ${ }^{14-16}$

It should be noted that the properties of quaternization agents have an important role in the antibacterial performance of PQACs. With the change of alkyl chain length ${ }^{14,17}$ and type of counter anions of the quaternization agents, ${ }^{18}$ the hydrophobic/hydrophilic balance and polarity of PQACs are changed, ${ }^{2,19-21}$ thus affecting the interaction between PQACs and bacterial cytoplasmic membranes. The most commonly used quaternization agents are alkyl halides. ${ }^{22}$ They are useful in preparing antibacterial PQACs; however, their industrial application is limited because they are time-consuming and expensive, and the problem becomes more acute with lengthening of the alkyl chain.

Therefore, we herein report the synthesis of a quaternary ammonium salt (QAS) monomer (2-trimethylamino) ethyl methacrylate methylsulfate (1) from 2-dimethylamino ethyl methacrylate (DMAEMA) and dimethyl sulfate (DMS). The corresponding homopolymers (2) were then obtained by free radical polymerization. Their potential for

1PCFM Laboratory, School of Chemistry and Chemical Engineering, Sun Yat-sen University, Guangzhou, PR China; ${ }^{2}$ DSAPM Laboratory, School of Chemistry and Chemical Engineering, Sun Yat-sen University, Guangzhou, PR China and ${ }^{3}$ Institute of Optoelectronic and Functional Composite Materials, Sun Yat-sen University, Guangzhou, PR China Correspondence: Professor R Fu, PCFM laboratory and Institute of Optoelectronic and Functional Composite Materials, Sun Yat-sen University, Guangzhou 510275, PR China. E-mail: cesfrw@mail.sysu.edu.cn

Received 6 April 2010; revised 30 May 2010; accepted 4 June 2010; published online 14 July 2010 
antibacterial application was established by antibacterial tests against Escherichia coli and Staphylococcus aureus.

As highlighted here, (1) could be easily achieved without energy consumption. The reaction between DMAEMA and DMS occurred once they came into contact with each other, causing detectable exothermal phenomena. Considering the much lower cost of DMS with respect to alkyl halides, this synthetic route to (1) and (2) has combined easy preparation, low cost and good antibacterial activity. The polymers might still retain good antibacterial activity if being immobilized on material surfaces, as the good water solubility allows them to stretch and contact bacteria cells freely. Therefore, it might be beneficial to use (1) in the antibacterial modification of material surfaces, so as to respond to the increasing need for the development of antibacterial materials.

\section{MATERIALS AND METHODS}

Materials

DMAEMA (98\%, Sigma-Aldrich, St Louis, MO, USA) was distilled under reduced pressure to remove the inhibitor before use. Hydroquinone and potassium persulfate (KPS) were purified by recrystallization. DMS, isopropanol, acetone, ethanol, acetonitrile and other solvents were purchased from Guangzhou Chemical Reagent Factory (Guangzhou, China) and used without further purification. Nutrient agar and nutrient broth were purchased from Guangdong Huankai Microbial Sci. \& Tech (Guangzhou, China).

\section{Synthesis of (2-trimethylamino) ethyl methacrylate methylsulfate (1)}

Synthesis of (1) was carried out as follows. A certain amount of DMAEMA and hydroquinone (molar ratio of hydroquinone/monomers $=0.4 \%: 1$ ) was added into a two-necked, round-bottom flask containing the solvent isopropanol. The isopropanol solution of DMS was then added dropwise into the flask. After the addition of DMS ( $\sim 20 \mathrm{~min})$, the solution was continuously stirred for a period of time and then refrigerated at $0{ }^{\circ} \mathrm{C}$. White powder was then precipitated out, filtrated, washed with ether several times, and finally freezedried. The yield of (1) was calculated according to the following equation:

Yield $/ \%=$ weight of precipitates $\times 100 /$ theoretical yield of products

\section{Synthesis of poly((2-dimethylamino) ethyl methacrylate methylsulfate) (2)}

The polymerization of (1) was carried out in a two-necked, round-bottom flask equipped with a condenser, a nitrogen inlet and a magnetic stirrer. Desired amounts of (1), initiator (KPS) and deionized water were added into the flask. After purified nitrogen was passed through the vessels for $0.5 \mathrm{~h}$, the system was heated to a predetermined temperature and stirred under $\mathrm{N}_{2}$ atmosphere. The polymerization was stopped by cooling down to room temperature. The products were separated by freeze-drying and purified by continuous extraction with a soxhlet extractor (Jintan Jinbo Co. Ltd., Jiangsu, China). The products were finally dried in a vacuum oven at $60^{\circ} \mathrm{C}$ for $48 \mathrm{~h}$.

\section{Structure characterization}

The infrared spectra were recorded from 400 to $4000 \mathrm{~cm}^{-1}$ on a Nicolet 210 infrared spectrophotometer (Madison, WI, USA) using $\mathrm{KBr}$ pellets. ${ }^{1} \mathrm{H}$-nuclear magnetic resonance spectra were collected on a FT-NMR (INOVA-500, Varian, Palo Alto, CA, USA) spectrometer using $\mathrm{D}_{2} \mathrm{O}$ as solvent.

\section{Determination of intrinsic viscosity}

Because homopolymers (2) were insoluble in tetrahydrofuran, their molecular weights (MW) were determined using the viscosity method instead of gel permeation chromatography. A certain amount of polymers was dissolved completely in $0.01 \mathrm{M} \mathrm{NaCl}$ and filtered with a suction filter. The time required for the solvent and sample solution to pass through the Ubbelhode viscometer (Shanghai Longtuo Co., Ltd., Shanghai, China) at $30^{\circ} \mathrm{C}$ was recorded and termed $t_{0}$ and $t$, respectively. Therefore, relative viscosity $\eta_{\mathrm{r}}$ and intrinsic viscosity $(\eta)$ were calculated by the following equations:

$$
\begin{aligned}
& \eta_{\mathrm{r}}=\frac{t}{t_{0}} \\
& \eta_{\mathrm{sp}}=\frac{\eta_{\mathrm{r}}-1}{C} \\
& {[\eta]=\lim _{c \rightarrow 0} \frac{\eta_{\mathrm{sp}}}{C}}
\end{aligned}
$$

\section{Antibacterial assessment}

Bacterial culture. The antibacterial activities of (1) and (2) were tested against Gram-positive S. aureus ATCC25932 and Gram-negative E. coli ATCC25922 using minimum biocidal concentration (MBC) value testing and the shaking flask method as described previously.22 The bacteria were streaked out on nutrient agar plates and incubated at $37^{\circ} \mathrm{C}$ for $24 \mathrm{~h}$. A representative colony was lifted off with a wire loop, placed in $50 \mathrm{ml}$ nutrient broth, and incubated by shaking at $37^{\circ} \mathrm{C}$ for $20 \mathrm{~h}$. At this stage, the concentration of bacteria suspension reached approximately $10^{9}$ colony-forming units per $\mathrm{ml}\left(\mathrm{CFU} \mathrm{ml}^{-1}\right)$. Working cultures at the required concentration were obtained by dilution with sterile nutrient broth.

$M B C$ test. The $\mathrm{MBC}$ value was used as a parameter to evaluate biocidal activity. The test was conducted as follows: $30 \mathrm{mg} \mathrm{ml}^{-1}$ copolymer solutions in deionized water were prepared in sterile test tubes and then two-fold diluted by sterile $0.1 \%$ peptone water. Two milliliters of each copolymer solution was mixed with $2 \mathrm{ml}^{1} 0^{6} \mathrm{CFU} \mathrm{ml}^{-1}$ bacteria suspension and then kept shaking at $37^{\circ} \mathrm{C}$ and 150 r.p.m. $\mathrm{min}^{-1}$ for $20 \mathrm{~h}$. At the end of the incubation, $100 \mu \mathrm{l}$ of solution was taken out, spread on the nutrient agar and incubated at $37^{\circ} \mathrm{C}$ overnight. The minimum concentration at which no bacteria survived was determined to be the $\mathrm{MBC}$ value. Each experiment was repeated twice.

Shaking flask method. Ten milliliters of sample solution was mixed with the same volume of bacteria suspension $\left(10^{8} \mathrm{CFU} \mathrm{ml}{ }^{-1}\right)$. The final concentration of (1) and (2) was 3.75 or $15 \mathrm{mg} \mathrm{ml}^{-1}$. The solution was then incubated at $37^{\circ} \mathrm{C}$ with shaking at 150 r.p.m. $\mathrm{min}^{-1}$ for $20 \mathrm{~h}$. At the end of the incubation, $1 \mathrm{ml}$ of solution was taken out and diluted with sterile $0.1 \%$ peptone water. The diluted solutions were spread on agar plates and incubated overnight at $37^{\circ} \mathrm{C}$. The number of surviving bacteria cells was calculated by multiplying the number of colonies by the dilution factors.

\section{RESULTS AND DISCUSSION}

Synthesis of (1)

The reaction temperature, time and feed ratio of DMS/DMAEMA were taken into account in the synthesis of DAMEMA-DMS. The yield was considered the evaluation factor.

It was found that DMS was very reactive toward DMAEMA. When the synthesis was carried out at room temperature $\left(30^{\circ} \mathrm{C}\right)$, an exothermic phenomenon was clearly observed as soon as DMS was added and caused an increase in reaction temperature. DMS solution was added dropwise for about $20 \mathrm{~min}$. Once the DMS was added, the mixed solution was found to cool down to room temperature in several minutes. The reaction was of high efficiency. As shown in Figure 1, just after the addition of DMS, the yield reached $87.6 \%$. If the reaction was continued for another $4 \mathrm{~h}$, the yield increased slightly, to $91 \%$.

The yield of (1) at different reaction temperatures was determined just after the addition of DMS. In general, the yield of (1) increased with reaction temperature. When the temperature increased from 0 to $30{ }^{\circ} \mathrm{C}$, the yield increased from 45 to $87 \%$ (See Table 1 ). Care should be taken in dealing with the increase in reaction temperature. When the reaction proceeded at $60{ }^{\circ} \mathrm{C}$ a side reaction occurred, and the 


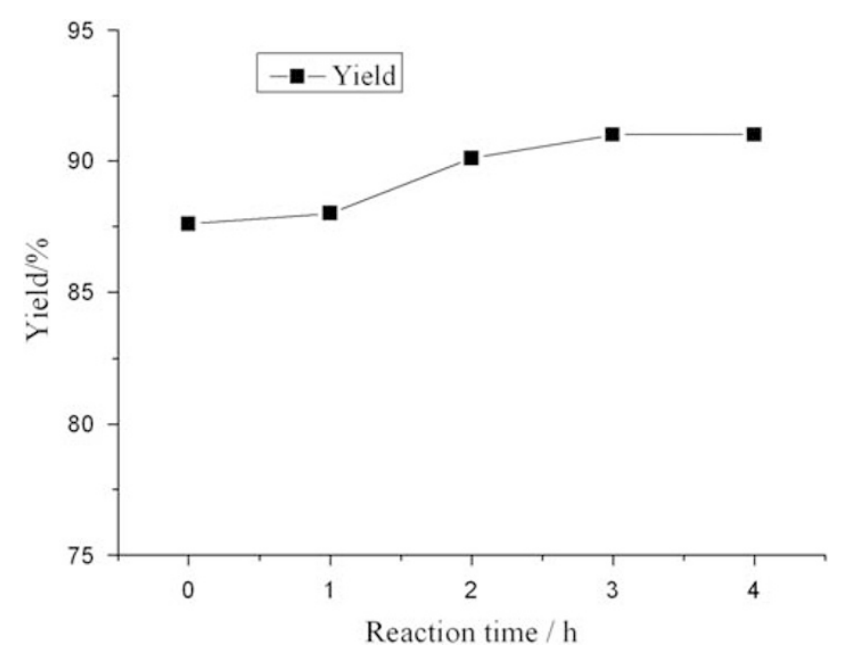

Figure 1 Effect of reaction time on the yield of (1). Reaction temperature, $30^{\circ} \mathrm{C}$; DMAEMA/DMS mole ratio, $1: 1$; hydroquinone/DMAEMA mole ratio, $0.4: 100$.

Table 1 Effect of reaction temperature on the yield of (1)

\begin{tabular}{lllll}
\hline Temperature $\left({ }^{\circ} \mathrm{C}\right)$ & 0 & 15 & 30 & 60 \\
\hline Yield $(\%)$ & 45 & 65 & 87 & Red solution mixture (side reaction) \\
\hline
\end{tabular}

mixed solution changed from colorless to red. This might be attributed to the reaction of the inhibitor hydroquinone at high temperature. Therefore, QAS monomer could be obtained from DMAEMA and DMS without energy consumption. A reaction temperature of $30{ }^{\circ} \mathrm{C}$ was recommended for the synthesis of (1).

The influence of the DMS/DMAEMA mole ratio is shown in Figure 2. When the mole ratio of DMS/DMAEMA increased from 0.68 to 1.13 , the yield of (1) increased from 47.1 to $93.1 \%$. Therefore, the amount of DMS had great influence on the yield of QAS monomer. When the dosage of DMS increased, more DMAEMA participated in the reaction, producing more QAS monomer.

The results summarized above sufficiently demonstrate the feasibility and efficiency of the synthetic route for (1). Therefore, DMS seems to be an attractive substitute for alkyl halides, which is time-consuming and expensive.

The chemical structure of (1) was characterized by Fourier transform infrared and ${ }^{1} \mathrm{H}$-nuclear magnetic resonance listed in Table 2. These data were in agreement with the theoretical structure of DAMEMA-DMS.

\section{Synthesis of (2)}

The QAS monomer (1) was polymerized by free radical polymerization using KPS as the initiator. The influence of polymerization time, temperature, concentration of monomer and initiator on the yield and MW (viscosity) of (2) was investigated. Because polymers (2) were insoluble in tetrahydrofuran, their MWs were determined by viscosimetric analysis.

As shown in Figure 3, the yield of (2) increased gradually with the increase of polymerization time. When the polymerization time was prolonged from 12 to $24 \mathrm{~h}$, the polymerization proceeded further, and the yield increased from 79 to $84 \%$. In contrast, the viscosity $\left(\eta_{\mathrm{sp}}\right)$ of the (2) solution decreased linearly from 73 to 62 . This might be

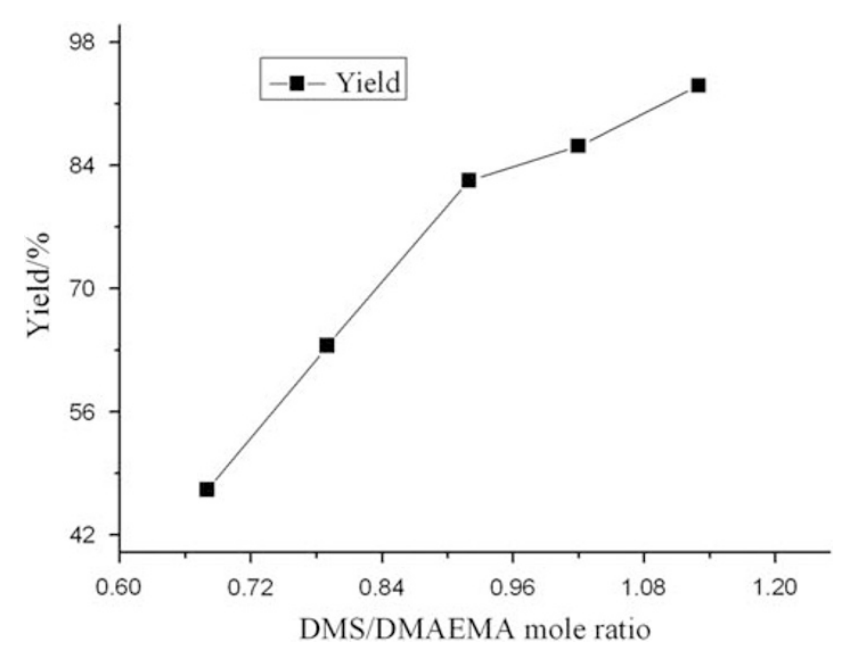

Figure 2 Effect of feed ratio on the yield of (1). Reaction temperature, $30^{\circ} \mathrm{C}$; hydroquinone/DMAEMA mole ratio, 0.4:100.

Table 2 Structure characterization of (1) and (2)

\begin{tabular}{|c|c|c|}
\hline & (1) & (2) \\
\hline $\begin{array}{l}\text { Fourier trans- } \\
\text { form infrared }\end{array}$ & $\begin{array}{l}1633 \mathrm{~cm}^{-1}(\mathrm{C}=\mathrm{C} \text { stretching } \\
\text { vibration), } 3092 \mathrm{~cm}^{-1} \\
\text { (=CH stretching vibration); } \\
1720 \mathrm{~cm}^{-1}(\mathrm{C}=0 \text { stretching } \\
\text { vibration); } 1179 \mathrm{~cm}^{-1} \\
\text { (C-O-C asymmetrical stretching } \\
\text { vibration); } 1362,1323,1178 \\
\text { and } 1207 \mathrm{~cm}^{-1}\left(\mathrm{RO}-\mathrm{SO}_{2}-\mathrm{OR}^{\prime}\right) ; \\
1060 \mathrm{~cm}^{-1}(-\mathrm{S}=\mathrm{O}-\text { stretching } \\
\text { vibration) }\end{array}$ & $\begin{array}{l}1727 \mathrm{~cm}^{-1}(\mathrm{C}=0 \\
\text { stretching vibration); } \\
1162 \mathrm{~cm}^{-1}(\mathrm{C}-\mathrm{O}-\mathrm{C} \\
\text { asymmetrical stretching } \\
\text { vibration); } 1362,1323 \text {, } \\
1178 \text { and } 1207 \mathrm{~cm}^{-1} \\
\left(\mathrm{RO}-\mathrm{SO}_{2}-\mathrm{OR}^{\prime}\right) ; \\
1069 \mathrm{~cm}^{-1}(-\mathrm{S}=0- \\
\text { stretching vibration) }\end{array}$ \\
\hline $\begin{array}{l}{ }^{1} \mathrm{H} \text {-nuclear } \\
\text { magnetic } \\
\text { resonance }\end{array}$ & $\begin{array}{l}\text { a(5.612 p.p.m.), b(6.018 p.p.m.), } \\
\text { c(1.675 p.p.m.), d(4.408 p.p.m.), } \\
\text { e(3.488 p.p.m.), f(3.074 p.p.m.), } \\
\text { g(3.625 p.p.m.). }\end{array}$ & $\begin{array}{l}\text { 1(1.919 p.p.m.), } \\
\text { 2(1.114 p.p.m.), } \\
\text { 3(4.479 p.p.m.), } \\
\text { 4(3.494 p.p.m.), } \\
\text { 5(3.220 p.p.m.), } \\
\text { 6(3.696 p.p.m.). }\end{array}$ \\
\hline
\end{tabular}

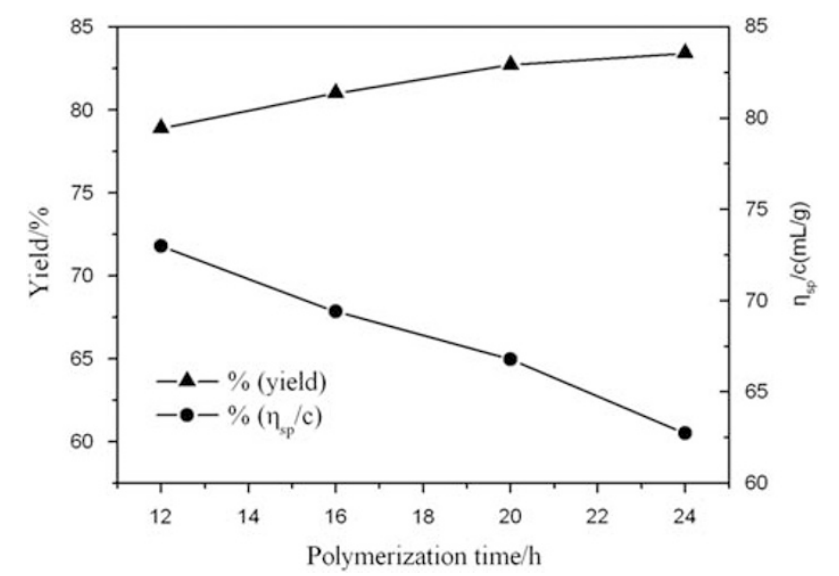

Figure 3 Effect of polymerization time on yield and molecular weight. Concentration of (1), 20 wt\%; KPS/(1) mass ratio, 0.4:100; polymerization temperature, $60^{\circ} \mathrm{C}$. 
attributed to the production of lower MW polymers, the amounts of which increased with polymerization time. The existence of lower MW polymers caused the reduction in viscosity of the whole sample.

A similar tendency was found in the effect of the KPS/(1) mass ratio, as shown in Figure 4. The yield increased slightly with the increase of KPS concentration, but the viscosity (MW) of (2) decreased significantly with it. When the KPS/(1) mass ratio increased from 0.2 to $1.0 \%$, the $\eta_{\text {sp }}$ decreased sharply from 69.2 to 36.0 . This was in accordance with the general features of free radical polymerization. With the increase of $\mathrm{KPS} /(\mathbf{1})$ mass ratio, more radical initiators were produced in the polymerization system. This was beneficial to the full polymerization of (1). However, yield lagged behind the increase of the KPS/(1) mass ratio. Therefore, with the increase of KPS concentration, the number of polymer molecules increased, and the degree of polymerization decreased. This resulted in the decrease of MW, which was expressed as the decrease of viscosity. Therefore, the amount of KPS was a potent tool in controlling the MW of (2).

Figure 5 shows clearly that both yield and $\eta_{\text {sp }}$ decreased with the increase of the monomer content if the KPS/(1) mass ratio was held constant. When content of (1) increased from 7.4 to $47.6 \mathrm{wt} \%$, the yield decreased slightly, from 83.1 to $75 \%$, and the $\eta_{\text {sp }}$ decreased to a

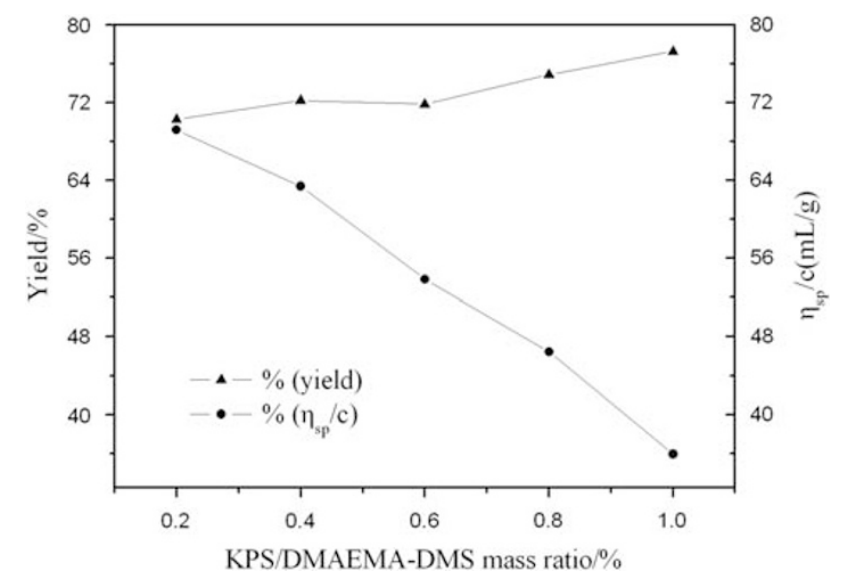

Figure 4 Effect of the concentration of KPS on yield and molecular weight. Concentration of (1), 20 wt \%; polymerization temperature, $60^{\circ} \mathrm{C}$; polymerization time, $16 \mathrm{~h}$.

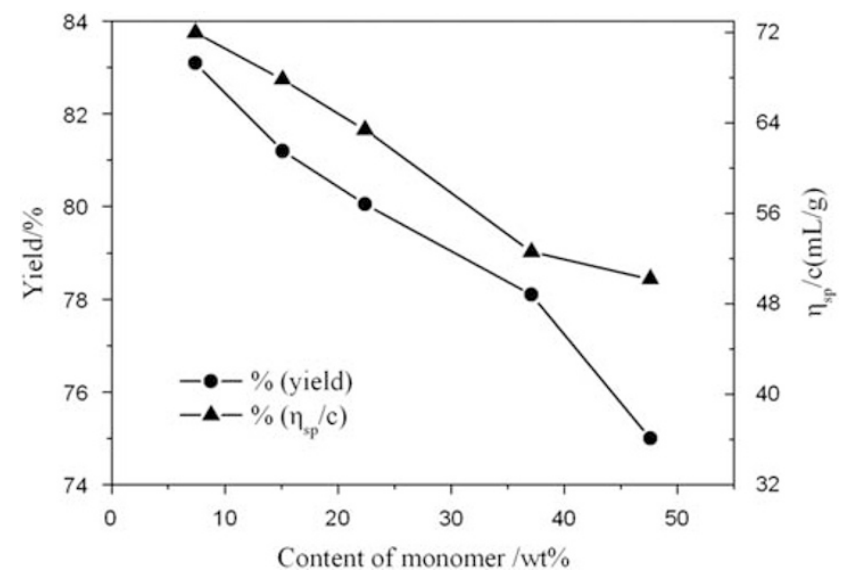

Figure 5 Effect of the concentration of monomer on yield and molecular weight. $\mathrm{KPS} /(\mathbf{1})$ mass ratio, $0.4: 100$; polymerization temperature, $60^{\circ} \mathrm{C}$; polymerization time, $16 \mathrm{~h}$. greater degree, from 72.0 to 50.2. The difference in response may have occurred because the viscosity of the reaction system increased with monomer content. It was unfavorable for the polymer radicals to contact with (1). Meanwhile, the concentration of polymer free radicals and initiator radicals in the system increased, which enhanced the termination rate of large molecular free radicals. This might have caused the reduction in yield and MW.

The effect of polymerization temperature on the yield and MW is shown in Figure 6. It was found that the yield increased gradually, and the rate tended to slow with the increase of temperature. In contrast, the $\eta_{\text {sp }}$ first increased with polymerization temperature and then decreased when the polymerization temperature was above $50{ }^{\circ} \mathrm{C}$. This could also be explained by the mechanism of free radical polymerization. The increase in polymerization temperature would accelerate the decomposition rate of KPS and enhance the polymerization reactivity of (1), which was beneficial for the complete polymerization of (1) and the increase of the yield of (2). However, the dependence of MW on polymerization temperature was somewhat complicated. The enhancement of monomer reactivity could have promoted the process of chain propagation and been beneficial for the increase in MW. However, the acceleration of the decomposition rate of KPS produced more free radicals in the reaction system. This meant that more free radicals were simultaneously contending for (1). At the same time, the rise in temperature also increased the chance of coupling termination and disproportionation termination of the polymerization, which consequently might have induced the decrease in MW. At different stages of polymerization, one of the two factors had the leading role and caused the increase or decrease in MW (viscosity).

The chemical structure of (2) was characterized by Fourier transform infrared and ${ }^{1} \mathrm{H}$-nuclear magnetic resonance (Table 2). These data were also in agreement with the theoretical structure of poly (DAMEMA-DMS).

\section{Antibacterial assay}

The antibacterial activity of as-prepared QAS monomer (1) and the corresponding polymers (2) was tested against E. coli and S. aureus using MBC value testing and the shaking flask method, the results of which are shown in Tables 3 and 4, respectively. In Table 3, it was seen that $\mathrm{MBC}$ values of the polymers were in the range of $0.5-5.0 \mathrm{mg} \mathrm{ml}^{-1}$ against E. coli and S. aureus, equivalent to $1.8-18 \mathrm{~mm}$. This was

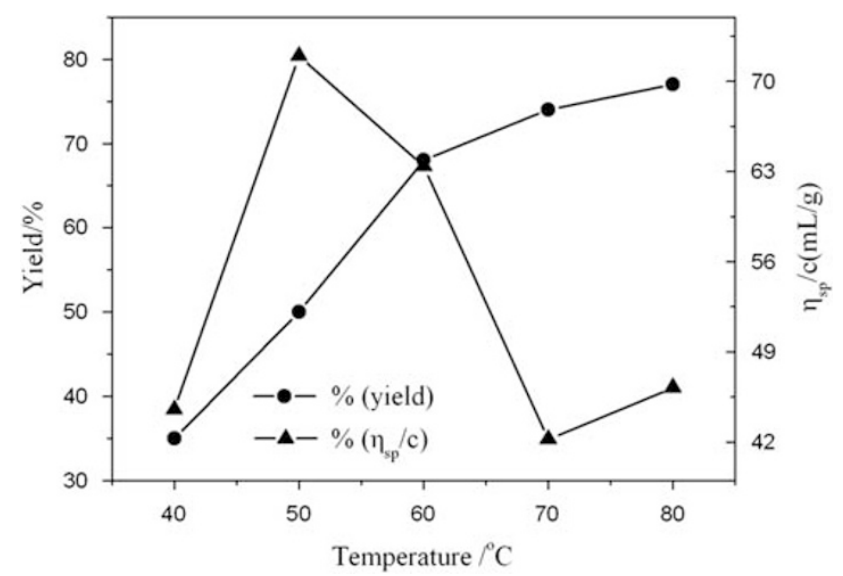

Figure 6 Effect of polymerization temperature on yield and molecular weight. Concentration of (1), 20 wt\%; KPS/(1) mass ratio, 0.4:100; polymerization time, $16 \mathrm{~h}$. 
Table $3 \eta_{\mathrm{sp}}$ and minimum biocidal concentration values of (1) and (2)

\begin{tabular}{lrcccc}
\hline & (1) & (2a) & (2b) & (2c) & (2d) \\
\hline$\eta \mathrm{sp}$ & - & 36.36 & 46.73 & 60.52 & 68.96 \\
S. aureus $\left(\mathrm{mg} \mathrm{ml}^{-1}\right)$ & $>30$ & 5.0 & 1.3 & 0.6 & 0.6 \\
E. coli $\left(\mathrm{mg} \mathrm{ml}^{-1}\right)$ & 15 & 1.2 & 2.5 & 0.6 & 1.2 \\
\hline
\end{tabular}

$2 \mathrm{a}, 2 \mathrm{~b}, 2 \mathrm{c}$ and $2 \mathrm{~d}$ were defined according to the $\eta_{\mathrm{sp}}$ of (2).

Table 4 The killing rate of (1) and (2) against E. coli and S. aureus

\begin{tabular}{lccccc}
\hline & \multicolumn{2}{c}{ (1) } & & \multicolumn{2}{c}{ (2b) } \\
\cline { 2 - 3 } \cline { 5 - 6 } Concentration $\left(\mathrm{mg} \mathrm{m}^{-1}\right)$ & 3.75 & 15 & & 3.75 & 15 \\
\hline E. coli $(\%)^{\mathrm{a}}$ & 63.2 & 99.9 & & 99.9 & 99.9 \\
S. aureus (\%) & 83.0 & 99.8 & & 99.6 & 99.6 \\
\hline
\end{tabular}

aThe killing rates were determined after incubating with the bacteria for $0.5 \mathrm{~h}$.

obviously better than that of the precursory monomer (more than $15 \mathrm{mg} \mathrm{ml}^{-1}$ ). Furthermore, it should be pointed out that the antibacterial activity of (2) was comparable with that of PQACs derived from alkyl halides. Therefore, DMS seemed to be a possible substitute for alkyl halides in the preparation of antibacterial QACs.

The enhancement of antibacterial activity might be due to the increase of local charge density by polymerization. In previous studies, the antibacterial action of QACs was believed to be as follows: (1) adsorption onto the negatively charged bacterial cell surface; (2) penetration through the cell wall; (3) binding to the cytoplasmic membrane; (4) disruption of the cytoplasmic membrane; (5) release of intracellular constituents such as $\mathrm{K}^{+}$, DNA and RNA; and (6) death of bacteria cells. $^{22,23}$ As the polymers have higher local charge density than the corresponding monomer, the process (1) is expected to have a large driving force. ${ }^{22,25}$ This might be the reason that (2) exhibited better antibacterial activity than (1).

The antibacterial performance of (2) also showed MW-dependent properties. The antibacterial activity against $S$. aureus increased steadily when $\eta_{\text {sp }}$ increased from 36.46 to 68.96 . No inflection point appeared in this region. This might also be due to the influence of local charge density, which has been proven to increase with MW in previous studies. Ikeda et al. ${ }^{26}$ prepared polymers with biguanide side chain groups, and found that the biocidal activity increased with MW up to $5 \times 10^{4} \mathrm{Da}$. Kanazawa et al. ${ }^{21}$ synthesized a series of poly (tributyl 4-vinylbenzyl phosphonium chloride) and found that their antibacterial activity increased with $\mathrm{MW}$ from $1.6 \times 10^{4}$ to $9.4 \times 10^{4} \mathrm{Da}$. Interestingly, some antibacterial polymers are even derived from inactive monomers. ${ }^{27}$

However, we do not fully understand the influence of MW on the antibacterial activity of (2) against $E$. coli. The best $\mathrm{MBC}$ value was obtained at the $\eta_{\mathrm{sp}}$ of 60.52 . Both increasing and decreasing the MW of (2) weakened the antibacterial activity against E. coli. This might be caused by the difference in bacteria cell envelope structure. $S$. aureus and E. coli are the typical representatives of Gram-positive and Gramnegative bacteria, respectively. Compared with Gram-positive bacteria, Gram-negative bacteria possess an extra outer membrane composed of phospholipids, proteins and lipopolysaccharides. The membrane is responsible for discharging a variety of environmental molecules and absorbing other necessary compounds selectively. ${ }^{27,28}$ Because of the outer membrane, E. coli is more resistant to antibacterial agents than is $S$. aureus. This might have caused the different response to antibacterial (2).

Antibacterial activity was further characterized by the shaking flask test, the results of which are shown in Table 4 . The killing rate increased with the dosage of (1) and (2). Similarly, the homopolymers (2) were more biocidal than the monomer (1), as $99.99 \%$ of $E$. coli were killed by $3.75 \mathrm{mg} \mathrm{ml}^{-1}(2)$, whereas only $63.2 \%$ were killed by the same amount of (1). A similar phenomenon was observed in the treatment of $S$. aureus.

\section{CONCLUSIONS}

In conclusion, an antibacterial quaternary ammonium acrylic monomer (1) was synthesized from the quaternization of DMAEMA with DMS. The reaction was very active at room temperature and did not need any extra energy, thus having high efficiency and yield. The corresponding homopolymers (2) were obtained by free radical polymerization, and the potential of (2) for antibacterial application was then established. It was found that (2) had significantly higher antibacterial activity than (1), although (1) exhibited moderate antibacterial activity. It was also found that the antibacterial activity was influenced by the MW and type of bacteria strain. Furthermore, homopolymers (2) were found to exhibit antibacterial activity comparable with that of some other PQACs derived from alkyl halides. Because of the good water solubility of homopolymers (2), they might retain the good antibacterial activity after being immobilized on the surface of various materials, as they can stretch and come into contact with bacterial cells freely. Therefore, DMS is an attractive substitute for alkyl halides. The application of DMS for preparing antibacterial PQACs has combined benefits of ease of operation, high efficiency, low cost and good antibacterial activity. This type of antibacterial PQACs is promising for use at large scale to prevent bacterial infection and protect human health.

\section{ACKNOWLEDGEMENTS}

This research was supported by the Project of NNSFC (50673101) and the Scientific Foundation of Guangdong (0711020600015, 2004A30404001).

1 Hong, K., Liu, N. \& Sun, G. UV-induced graft polymerization of acrylamide on cellulose by using immobilized benzophenone as a photo-initiator. Eur. Polym. J. 45, 2443-2449 (2009).

2 Roy, D., Knapp, J., Guthrie, J. \& Perrier, S. Antibacterial cellulose fiber via RAFT surface graft polymerization. Biomacromolecules. 9, 91-99 (2008)

3 Ignatova, M., Voccia, S., Gilbert, B., Markova, N., Cossement, D., Gouttebaron, R., Jerome, R. \& Jerome, C. Combination of electrografting and atom-transfer radical polymerization for making the stainless steel surface antibacterial and protein antiadhesive. Langmuir. 22, 255-262 (2006)

4 Voccia, S., Ignatova, M., Jerome, R. \& Jerome, C. Design of antibacterial surfaces by a combination of electrochemistry and controlled radical polymerization. Langmuir. 22, 8607-8613 (2006).

5 Beyth, N., Yudovin-Farber, I., Bahir, R., Domb, A. \& Weiss, E. Antibacterial activity of dental composites containing quaternary ammonium polyethylenimine nanoparticles against Streptococcus mutans. Biomaterials. 27, 3995-4002 (2006).

6 Lu, G., Kong, L., Sheng, B., Wang, G., Gong, Y. \& Zhang, X. Degradation of covalently cross-linked carboxymethyl chitosan and its potential application for peripheral nerve regeneration. Eur. Polym. J. 43, 3807-3818 (2007)

7 Patel, J., Patel, S., Talpada, N. \& Patel, H. Bioactive polymers: synthesis, release study and antimicrobial properties of polymer bound Ampicillin. Die. Angewandte. Makromolekulare. Chemie. 271, 24-27 (1999).

8 Anyaogu, K., Fedorov, A. \& Neckers, D. Synthesis, characterization, and antifouling potential of functionalized copper nanoparticles. Langmuir. 24, 4340-4346 (2008).

9 Iconomopoulou, S. \& Voyiatzis, G. The effect of the molecular orientation on the release of antimicrobial substances from uniaxially drawn polymer matrixes. J. Control. Release. 103, 451-464 (2005).

10 Sambhy, V., MacBride, M., Peterson, B. \& Sen, A. Silver bromide nanoparticle/polymer composites: dual action tunable antimicrobial materials. J. Am. Chem. Soc. 128, 9798-9808 (2006). 
11 Sauvet, G., Fortuniak, W., Kazmierski, K. \& Chojnowski, J. Amphiphilic block and statistical siloxane copolymers with antimicrobial activity. J. Polym. Sci. Polym. Chem. 41, 2939-2948 (2003).

12 Kenawy, E., Abdel-Hay, F., El-Shanshoury, A. \& El-Newehy, M. Biologically active polymers. V. Synthesis and antimicrobial activity of modified poly(glycidyl methacrylate-co-2-hydroxy -ethyl methacrylate) derivatives with quaternary ammonium and phosphonium salts. J. Polym. Sci. Polym. Chem. 40, 2384-2393 (2002).

13 Marini, M., Bondi, M., Iseppi, R., Toselli, Z. \& Pilati, F. Preparation and antibacterial activity of hybrid materials containing quaternary ammonium salts via sol-gel process. Eur. Polym. J. 43, 3621-3628 (2007).

14 Tiller, J., Liao, C., Lewis, K. \& Klibanov, A. Designing surfaces that kill bacteria on contact. PNAS. 98, 5981-5985 (2001).

15 Matsugi, T., Saito, J., Kawahara, N., Matsuo, S., Kaneko, H., Kashiwa, N., Kobayashi, M. \& Takahara, A. Surface modification of polypropylene molded sheets by means of surface-initiated ATRP of methacrylates. Polym. J. 41, 547-554 (2009).

16 Matsugi, T., Saito, J., Kawahara, N., Matsuo, S., Kaneko, H., Kashiwa, N., Kobayashi, M. \& Takahara, A. Surface modification of polypropylene molded sheets by means of surface-initiated ATRP of methacrylates. Polym. J. 41, 547-554 (2009).

17 Domagk, G. A new class of disinfectants. Deut. Med. Wochenschr. 61, 829-32 (1935).

18 Pernak, J., Kalewska, J., Ksycinska, H. \& Cybulski, J. Synthesis and anti-microbial activities of some pyridinium salts with alkoxymethyl hydrophobic group. Eur. J. Med. Chem. 36, 899-907 (2001).

19 Cheng, Z., Zhu, X., Shi, Z., Neoh, K. \& Kang, E. Polymer microspheres with permanent antibacterial surface from surface-initiated atom transfer radical polymerization. Ind. Eng. Chem. Res. 44, 7098-7104 (2005).
$20 \mathrm{Hu}$, F., Neoh, K., Cen, L. \& Kang, E. Antibacterial and antifungal efficacy of surface functionalized polymeric beads in repeated applications. Biotechnol. Bioeng. 89, 474-484 (2005).

21 Kanazawa, A., Ikeda, T. \& Endo, T. Polymeric phosphonium salts as a novel class of cationic biocides. II. Effects of counter anion and molecular weight on antibacterial activity of polymeric phosphonium salts. J. Polym. Sci. Polym. Chem. 31, 1441-1447 (1993).

$22 \mathrm{Lu}$, G., Wu, D. \& Fu, R. Studies on the synthesis and antibacterial activities of polymeric quaternary ammonium salts from dimethylaminoethyl methacrylate. React. Funct. Polym. 67, 355-366 (2007).

23 Tatsuo, T. Antibacterial and bacterium adsorbing macromolecules. Macromol. Mater. Eng. 286, 63-87 (2001).

24 Murata, H., Koepsel, R., Matyjaszewski, K. \& Russell, A. Permanent, non-leaching antibacterial surfaces-2: how high density cationic surfaces kill bacterial cells. Biomaterials. 28, 4870-4879 (2007).

25 Kugler, R., Bouloussa, O. \& Rondelez, F. Evidence of a charge-density threshold for optimum efficiency of biocidal cationic surfaces. Microbiology, 151, 1341-1348 (2005).

26 Ikeda, T., Hirayama, H., Ymaguchi, H., Tazuke, S. \& Watanabe, M. Polycationic biocides with pendant active groups: molecular weight dependence of antibacterial activity. Antimicrob. Agents. Ch. 30, 132-136 (1986).

27 Lenoir, S., Pagnoulle, C., Galleni, M., Compere, P., Jerome, R. \& Detrembleur, C. Polyolefin matrixes with permanent antibacterial activity: preparation, antibacterial activity, and action mode of the active species. Biomacromolecules. 7, 2291-2296 (2006).

28 Kebir, N., Campistron, I., Laguerre, A., Pilard, J., Bunel, C. \& Jouenne, T. Use of telechelic cis-1,4-polyisoprene cationomers in the synthesis of antibacterial ionic polyurethanes and copolyurethanes bearing ammonium groups. Biomaterials. 28, 4200-4208 (2007). 